DIGITALCOMMONS

— @WAYNESTATE -
Michigan Journal of Counseling:

Research, Theory and Practice

$8-1-2002$

\title{
Social Skills Training For Aggressive Children In School Counseling: Implications Of Current Understanding Of Subtypes Of Aggressive Children
}

Jina S. Yoon

Wayne State University, jyoon@wayne.edu

Rochelle M. Broder

Wayne State University

Follow this and additional works at: https://digitalcommons.wayne.edu/mijoc

\section{Recommended Citation}

Yoon, J. S., \& Broder, R. M. (2002). Social Skills Training For Aggressive Children In School Counseling: Implications Of Current Understanding Of Subtypes Of Aggressive Children, Dimensions of Counseling, 30(2), 1-7. doi:10.22237/mijoc/1028160060

This Article is brought to you for free and open access by the Open Access Journals at DigitalCommons@WayneState. It has been accepted for inclusion in Michigan Journal of Counseling: Research, Theory and Practice by an authorized editor of DigitalCommons@WayneState. 


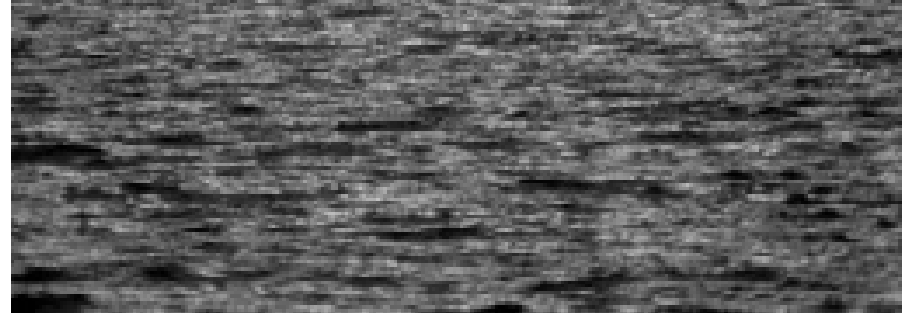

\section{Social Skills Training For Aggressive Children In School Counseling: Implications Of Current Understanding Of Subtypes Of Aggressive Children}

\section{Jina S. Yoon, Ph.D. Rochelle M. Broder, M.A.}

Wayne State University

Jina Yoon is an Assistant Professor in Educational Psychology at Wayne State University. Rochelle Broader is a school psychologist in Troy School District and a doctoral candidate in Educational Psychology at Wayne State University. Correspondence concerning this article should be addressed to Jina Yoon, Educational Psychology, College of Education, Wayne State University, Detroit, Michigan 48202. Email address: jyoon@wayne.edu
Social skills intervention (SSI) is one of the most popular choices for many school counselors when working with children who exhibit a wide range of behavior problems. However, a review of research findings indicates that social skills training has limited treatment efficacy in improving the social competence of children with behavior problems. Heterogeneous characteristics of these children may offer one explanation for the limited success of social skills training. This article reviews empirical research findings on the two forms of aggression (reactive aggression and proactive aggression) and proposes more individually tailored SSI as a way to improve its efficacy. Implications for social skills intervention are discussed. ggression is one of the most common problems in school-aged children and is dramatically increasing (Loeber, 1990). Aggressive and hostile children are described as disruptive, coercive, and demanding in class. Teachers are often overwhelmed by their challenging behaviors, and much of instruction time is taken for disciplining these children. Many interpersonally hostile, aggressive children are referred to school counselors and school psychologists and one of the frequently recommended services for them is social skills training. A variety of social skills training programs have been developed by researchers and practitioners with different emphases. Although these programs may use different formats (i.e., individual vs. group) or media (i.e., mentor, peer, psychologist/counselor), they share the assumption that aggressive children have not acquired developmentally appropriate social skills (i.e., skill deficits) and will acquire these skills through learning experiences such as structured instruction and/or 
exposure to prosocial situations. The purposes of this article are to provide a brief overview of social skills intervention, review the current literature on the two forms of aggressive behaviors (reactive vs. proactive aggression), highlighting the distinctive behavioral and social cognitive patterns associated with each, and finally to examine specific implications of this literature in terms of clinical utility in devising strategies for social skills intervention.

\section{Current Literature of Social Skills Intervention}

Although social skills intervention (SSI) is considered to be effective, the magnitude of observable changes in social behaviors has been disappointing. Lack of generalizing effects over time and across situations has been identified as a significant concern in the SSI literature (Elliot, Sheridan, \& Gresham, 1989; Sheridan \& Walker, 1999). Meta-analytic reviews concluded that social skills training with 3- to 15year olds yields minor short-term improvement but does not change those social behaviors of children that would have long-term effects on social relationships (Beelmann, Pfingsten, \& Lösel, 1994). A number of issues have been raised in efforts to improve the effectiveness of SSI. One recommendation was that social skill deficits that may be unique to individuals should be identified prior to the implementation of SSI programs (Beelmann, Pfingsten, \& Lösel, 1994). Gresham (1998) criticized practitioners who take a "one size fits all" (p. 22) approach and ignore the types of social skills that children may need to learn. Moreover, it was argued that a majority of studies do not identify specific social skill deficits and the interventions were usually provided with particular emphasis on anger control, perspective-taking ability, and/or social problemsolving approach.

Consistent with Gresham's (1998) call for more individually tailored SSI programs, an ecologicalbehavioral framework was proposed by Sheridan \& Walker (1999). Within their framework, social skills are conceptualized as "a function of the interaction of a child with others in a certain context" (p. 688). They suggested that an emphasis that focuses only on child characteristics (i.e., lack of perspective taking ability) in social skills training can lead to limited efficacy because equally important contextual variables (e.g., peer characteristics, flexibility of setting) that may maintain socially incompetent behaviors are not addressed in the programs. Thus, the ecological-behavioral approach urges practitioners to identify not only socially incompetent behaviors (skill deficits), but also functions of the behaviors within the context.

The ecological-behavioral framework in social skills intervention deserves special attention, considering the increasing empirical evidence that socially incompetent behaviors result from different mechanisms of multiple factors. For example, developmental psychologists identified different forms of aggressive behaviors among children and adolescents and investigated the relationship among different types of aggressive behaviors, social competence and peer relation (Crick \& Dodge, 1996; Henington, Hughes, Cavell, \& Thompson, 1999; Price \& Dodge, 1989). This body of literature indicates that interpersonally hostile, aggressive behaviors are developed and maintained by different sets of social skills deficits and social goals as well as different sets of contextual variables.
Despite continuing discussion and empirical support for SSI programs that are more sensitive to individual needs, little has been discussed as to how current understanding of different types of aggressive children can assist practitioners to conceptualize social skills training within an ecological-behavioral framework.

\section{Theoretical Definition of Reactive vs. Proactive Aggression}

Based on previous theory and research on aggression (Bandura, 1973; Hartup, 1974), Dodge and Coie (1987) examined two types of aggressive behaviors: reactive and proactive. Proactive aggression (PA) includes behaviors such as coercion, dominance, bullying, and instrumental aggression. These behaviors are considered proactive in that one engages in them without provocation as a means to achieve specific positive outcomes (i.e., dominance or intimidation of others). Therefore, PA is internally motivated, maintained by external rewards and is conceptualized as more controlled aggression than reactive aggression. In contrast, reactive aggression (RA) is defined as a defense reaction with anger and hostility to any perceived threat. It is believed that the perception of a threat triggers strong negative affect such as anger and frustration, which then leads to a hostile act. RA is also assumed to be a more impulsive, out of control behavior than proactive aggression. According to these definitions, the PA and RA are initiated and maintained by different goals and provocation. 


\section{Behavioral and Social Cognitive Characteristics}

A number of studies have documented empirical support for the theoretical distinction between reactive and proactive aggression. Waschbusch, Willoughby, \& Pelham (1998), for example, found that RA is more highly associated with poor adjustment as rated by teachers and peers than PA is. Specifically, reactive-proactive and reactive boys were viewed as most aggressive and ineffective in problem-solving and negotiating abilities (Day, Bream \& Pal, 1992). Children rated as reactive aggressive or mixed aggressive were more likely to have an impulsive response style than children without a reactive aggressive tendency. Furthermore, reactiveaggressive children were less accurate in terms of their ability to discern others' intent than children who did not exhibit reactive aggression (Dodge, \& Coie, 1987). In addition, reactive-aggressive children attributed more hostile intent in response to ambiguous provocation. These problems were not found among proactive aggressive children (Crick \& Dodge 1996; Dodge \& Coie, 1987). The use of reactive aggression was also associated with negative social preference, social withdrawal, and peer victimization (Poulin \& Boivin, 2000). The results remained the same even after the variance shared with proactive aggression was partialled out. RA children (1) were not skilled at detecting others' intent; (2) perceived others as hostile and "coming after them," and thus felt easily threatened or provoked; and (3) impulsively responded with anger and frustration in an "out-ofcontrol" manner. Peers seemed to view the aggressive behavior of a reacting child as inappropriate and dislikable, as evidenced by negative social preference. Peers responded to the reacting child with hostile and aggressive responses, which would confirm the initial hostile interpretation by a RA child that peers were mean and antagonistic.

The research paints a very different picture for proactiveaggressive (PA) children. They were viewed as less aggressive than reactive-proactive and reactive children, but slightly more aggressive than nonaggressive children (Day, Bream, \& Pal, 1992). In contrast to RA children, PA children did not show hostile attribution or intention-cue detection deficits. Instead, they evaluated physical and verbal aggression in significantly more positive ways than children who were not proactively aggressive (Crick \& Dodge, 1996). A comparison of proactive-aggressive children's social goals suggest that they engaged in the aggressive behaviors in order to attain goals that are instrumental or self-enhancing in nature, as opposed to social goals that would enhance their interpersonal relationships. Moreover, they reported significantly higher levels of confidence in enacting aggression than nonproactive children. The set of beliefs among PA children (high self-efficacy, positive evaluation of aggressive responses, and expectation of positive

\section{Table 1: Empirically Documented Characteristics of Reactive and Proactive Aggression}

\begin{tabular}{|c|c|c|}
\hline & Reactive Aggression & Proactive Aggression \\
\hline $\begin{array}{l}\text { Developmental History } \\
\text { Dodge, et al., } 1990\end{array}$ & $\begin{array}{l}\text { Early onset of problem behavior rated by teachers } \\
\text { Negative early experiences such as abuse }\end{array}$ & No problems rated by teachers in Kindergarten \\
\hline $\begin{array}{l}\text { Behavioral-Emotional } \\
\text { Day, Bream, \& Pal, } 1992 \\
\text { Goins-Flanagan, } 1999 \\
\text { Waschbusch, et al., } 1998 \\
\text { Schwartz, et al., } 1998 \\
\text { Dodge \& Coie, } 1987\end{array}$ & $\begin{array}{l}\text { Aggressive, impulsive, unhappy } \\
\text { Easily frustrated } \\
\text { Greater overall impairment beyond aggression; } \\
\text { increased likelihood of comorbidity } \\
\text { Prosocial skill deficits } \\
\text { Frequent display of submissive behavior }\end{array}$ & $\begin{array}{l}\text { Less aggressive than reactive type, more aggressive than average child } \\
\text { Sense of humor } \\
\text { Frequent display of assertive nonaggressive behavior }\end{array}$ \\
\hline $\begin{array}{l}\text { Peer Relation } \\
\text { Brown, et al., } 1996 \\
\text { Price \& Dodge, } 1989 \\
\text { Poulin \& Boivin, } 2000\end{array}$ & $\begin{array}{l}\text { Unpopular/rejected by peers } \\
\text { Social withdrawal and victimization by peers }\end{array}$ & $\begin{array}{l}\text { Viewed as a leader } \\
\text { Less rejected than reactive children }\end{array}$ \\
\hline $\begin{array}{l}\text { Social Cognitive Processing } \\
\text { Crick \& Dodge, } 1996 \\
\text { Smithmyer, et al., } 2000\end{array}$ & Hostile attribution & $\begin{array}{l}\text { Do not show hostile attribution or intention-cue detection deficits } \\
\text { Positive outcomes expectancies of aggressive responses } \\
\text { Values aggression/high self-efficacy for aggression }\end{array}$ \\
\hline
\end{tabular}


outcome) is consistent with the definition that proactive aggression is planned and motivated by the positive outcome (Dodge \& Coie, 1987).

Brown, Atkins, Osborn, \& Milnamow (1996) found that proactive aggression was not associated with negative peer status whereas reactive aggression was. Price and Dodge (1989) found that proactive aggression was associated with both negative and positive peer status, depending on the two forms of proactive aggression (bullying and instrumental): among first grade students, bullying was associated with negative peer status whereas instrumental aggression was associated with positive peer status. However, the reverse pattern was found in another study (Dodge, Coie, Pettit, \& Price, 1990). More consistent is the finding that as a group, proactive-aggressive children are viewed as having positive characteristics such as leadership (Poulin \& Boivin, 2000) and as having a good sense of humor (Dodge \& Coie, 1987). Taken together, these findings suggest that in contrast to reactiveaggressive children, proactive-aggressive children enjoy some level of peer support in spite of their use of aggressive acts. It was speculated that some children may view domineering and goal-oriented aggression as assertive and socially competent (Price \& Dodge, 1989).

The behavioral and social cognitive differences between proactively and reactively aggressive children have broadened the understanding of heterogeneity among aggressive children. These differences in developmental history, behavioral/emotional adjustment and social cognition are summarized in Table 1.

Reactive-aggressive children are more impulsive and inattentive than proactive-aggressive children. These behavioral patterns are linked to social skill deficits in self-control and inaccurate interpretation of social situations. RA children do not show appropriate prosocial behaviors and tend to be submissive, often victimized by peers. Meanwhile, PA children are described to have no problems in self-regulation and attention. Instead, proactive aggression is instrumental in nature and is primarily maintained by a belief that aggression leads to positive consequences. At the same time, they feel highly competent about their aggressive acts toward their peers. They exhibit some positive characteristics such as sense of humor and assertive nonaggressive behaviors, and are viewed as leaders by peers. hese different

profilles associated

with the two types

of aggression

persuasively argue

that different

behavioral and

cognitive variables

are involved in

initiation and

maintenance of

aggressive

behaviors, and that

these children do not

share the same

social skill deficits.
More importantly, these different profiles associated with the two types of aggression persuasively argue that different behavioral and cognitive variables are involved in initiation and maintenance of aggressive behaviors, and that these children do not share the same social skill deficits. It is also clear that intervention programs should address unique problems for proactively and reactively aggressive children.

Accordingly, as Poulin and Boivin (2000) suggested, predominance of each type of aggression should be appropriately determined in order to choose the most appropriate intervention.

\section{Assessment of Reactive and Proactive Aggression}

The purpose of assessment prior to social skills training is to identify specific social skill deficits for an individual child so that the deficits can be addressed in training. As is preferred from a measurement perspective, social skills must be evaluated using multiple sources (self-report, teacher, parent, and peer), different assessment methods (interview, behavior checklist, observation, sociometric techniques) and multiple contexts (playground, classroom, and home). The current discussion is limited to commonly used assessment methods and critical issues when taking reactive and proactive aggression into consideration. For a comprehensive review of social skills assessment, the readers are referred to Sheridan, Hungelmann, and Maughan (1999).

\section{Assessment of Child Characteristics}

Teacher rating is the most common approach in assessment of the two types of aggression and two teacher rating scales are available. The Teacher Rating of Reactive and Proactive Aggressive Behaviors (Dodge \& Coie, $1987)$ is a 6-item questionnaire. Teachers are requested to rate children on a 5 -point Likert Scale $(1=$ never, $5=$ almost always). The questionnaire includes three items each for reactive and proactive aggression. Reactive aggression items are "overreacts angrily to accidents," "when teased, strikes back" and "blames others in fights." Proactive aggression items are "gets others to gang up on a peer," "uses physical force to dominate," and "threatens and bullies others." A Revised Teacher Rating for Reactive and Proactive Aggression is a 28-item rating scale (Brown, Atkins, Osborn, Milnamow, 1996). The items are presented on a 3 -point Likert scale $(0=$ never, $2=$ very often). In an attempt to address the limited range of the proactive-aggressive behaviors that were assessed in the 
Teacher Rating of Reactive and Proactive Aggressive Behaviors, a covert antisocial scale (instrumental-proactive aggression) is also included. Furthermore, seven items on prosocial behavior allow one to examine social skills, in which reactive-aggressive children seem to have more problems. Both of these teacher-rating scales have empirical support for reliability and validity. It is clear that teachers can discriminate the two forms of aggression and provide valuable information about the different nature of aggressive behaviors.

Teacher ratings for reactive and proactive aggression should be used in conjunction with a standardized behavior checklist that assesses a wide range of behavioral, social, and emotional areas (i.e., the Child Behavior Checklist, Achenbach, 1983, or the Behavior Assessment System for Children, Reynolds, \& Kamphaus, 1992). For example, a standardized behavior checklist will assist one to determine the level of aggressive/disruptive behaviors. When a clinically significant level of aggression is present, teacher ratings on the two types of aggression will provide further understanding of the nature of the aggression. In addition, results of behavioral checklists will provide further information regarding level of impulsivity and emotional regularity. An elevated level of impulsivity, social withdrawal and unhappiness are more likely to be expected for children who show reactive aggression. Meanwhile, children with proactive aggression may actually enjoy some level of social support, but do not have an impulsive response style.

\section{Assessment of Contextual Variables}

Because ratings of the child do not offer information regarding ecological conditions where aggressive behaviors take place (i.e., antecedents and consequences), it is also important to identify how specific social skills deficits play out to produce aggressive behaviors and how these behaviors (reactive vs. proactive aggression) are controlled or maintained by the social context. Consistent with this approach, Sheridan and Walker (1999) provided a comprehensive review of different assessment methods (observation, sociometric techniques, and interview). One of the recommended procedures in social skills assessment is direct observation. Observation of an aggressive child in natural settings, such as on the playground, not only validates the teacher ratings described above, but also identifies environmental stimuli associated with specific aggressive behaviors.

The observation should be guided by the different behavioral criteria described for reactive and proactive aggression (see Dodge \& Coie, 1987; Schwartz, et al., 1998, for specific coding definitions). For example, an observer can identify what triggers a reactive-aggressive behavior and how peers react to the aggressive child. The observation may also reveal how well the aggressive child regulates negative emotions, which, if identified as a problem, should be an important part of social skills training. On the other hand, when a proactive-aggressive behavior is observed, specific social goals that motivate a particular child to be aggressive must be identified. As discussed above, the child may be proactively aggressive either to intimidate a classmate (dominance) or to obtain an object (instrumental) or both.

A particularly important contextual factor to be examined during the assessment phase is immediate consequence: how teachers intervene, how tolerant peers are, etc. Considering that the event following proactive aggression has a considerable amount of influence on the likelihood of the aggressive behavior to occur in the future, responses from peers and teacher should be thoroughly investigated. Given that some proactive aggression frequently occurs on the playground and has a covert nature, it may be that teachers are not aware of all the aggressive exchanges among children.

\section{Social Skills Intervention For Reactive- And Proactive-aggressive Children.}

Given the different characteristics of reactive and proactive aggressive children, it is evident that social skills training should be tailored to meet their unique needs. Reactive-aggressive children would be expected to benefit from social skill interventions that promote emotional regulation skills and prosocial skills. Greenberg's PATHS Program (Greenburg, Kusche, Cook, \& Quamma, 1996) and Lochman's Coping Power Program (Lochman \& Lenhart, 1993) have a strong emphasis on emotional regulation skills and have been found to reduce levels of aggression. With better regulation of emotional arousal, RA children may be less explosive and out of control in a peer context. Selfmonitoring techniques can also help RA children become more aware of their impulsive response style, emotional reaction, and associated consequences. Because inappropriate emotional display and defensive hostility are a major concern for RA children, increased awareness of their own behavior and greater self-control may reduce their tendency to be aggressive and hostile.

Peer modeling is another strategy recommended in social skills training for RA children. Socially skilled peers not only provide role models for appropriate social skills, but also reduce stigmatizing effects of participation in a social skills program (Prinz, Blechman \& Dumas, 1994). Including prosocial peers in social skills training may be particularly important for reactive-aggressive children, who experience negative peer relationship. Bierman and Furman (1984) found that children who learned conversational social skills with peers experienced greater peer acceptance and improved self-concept compared to 


\section{Table 2. Differential Intervention of Reactive and Proactive Aggressive Children}

\begin{tabular}{|c|c|c|}
\hline & INTERVENTIONS & RATIONALE \\
\hline RA & $\begin{array}{l}\text { - Promote emotional regulation/arousal } \\
\text { - Promote prosocial skills } \\
\text { - Self-monitoring techniques } \\
\text { - Awareness and self-control } \\
\text { - Peer modeling }\end{array}$ & $\begin{array}{l}\text { - Increase positive peer relationships and self-concept } \\
\text { - Reduce stigmatizing effects of participation in social skills program } \\
\text { - Develop assertiveness and become less victimized }\end{array}$ \\
\hline PA & $\begin{array}{l}\text { - Social skills program that ameliorates belief that } \\
\text { - } \text { aggression is legitimate and effective } \\
\text { - } \text { - Encoss consequential thinking, role-taking ability, empathy } \\
\text { - Improve ability to identify and understand victim's affect } \\
\text { - Capitalize on positive social behaviors by reinforcing them when they are prosocial }\end{array}$ & - Promoting relationship enhancing social goals and prosocial behaviors \\
\hline
\end{tabular}

the participants without a facilitating peer during instruction. As RA children acquire social skills and gain higher social competence, they will become more assertive and less victimized.

Given that PA children do not have the same social skill deficits of RA children, it is unlikely that PA children would benefit from the same type of SSI. PA children are most likely to benefit from a social skills program that ameliorates their belief that aggression is legitimate and effective. A SSI program might stress consequential thinking, role-taking ability, and empathy as a way to reduce proactive aggression. PA children should be encouraged to consider negative outcomes of their aggression. At the same time, their ability to identify and understand victims' affect should be improved. As undesirable consequences (i.e., punishment) and devastating impact on the victim are considered, their egocentric focus on positive outcome from aggressive acts may decrease. Chandler (1973) implemented an intervention that targeted role-taking abilities of delinquent youths. The results indicated that the training not only increased role-taking abilities, but also reduced delinquent behaviors in an 18-month follow-up. In addition, PA children seem to have some level of positive social behavior. This needs to be capitalized upon within SSI by recognizing and reinforcing them when prosocial behaviors are shown, thus promoting relationship enhancing social goals and prosocial behaviors.

The distinctive behavioral and social cognitive profiles found between RA and PA also raise another important treatment issue. Arnold and Hughes (1999) cautioned that grouping aggressive and antisocial children and adolescents can lead to potential harmful effects of SSI. Based on our current understanding of RA and PA, it is plausible that when aggregated in a group, socially incompetent RA children can be provoked by PA children and react to the provocation in a hostile/aggressive manner. In return, PA children may enact retaliatory aggression, consistent with their social goal of dominance and coercion. In this context, it is possible to engage in a cycle whereby RA children become repeated recipients / victims of PA children, in turn confirming perceived threats by RA children. At the same time, PA children's deviant interpersonal tactics may be continuously reinforced, supporting their biased beliefs toward aggression and increasing their confidence. Given that a group treatment is a common format of SSI, one has to evaluate impacts of including RA and PA children in a group together. Awareness of possible problems and continued monitoring will be necessary to prevent unintended outcomes of SSI. Table 2 summarizes differential interventions that may be used with RA and PA children. Due to lack of empirical data that examines this issue, a question of whether aggregating RA and PA children in a SSI group is related to any specific treatment outcome deserves future investigation.

\section{Conclusion}

An individualized approach in assessment and treatment of aggressive children is not a new idea and has been repeatedly called for in the literature. However, as Gresham (1998) critically pointed out, teaching social skills such as anger management and prosocial behaviors without appropriate assessment continue to be a major problem. In the present article, we urge practitioners to adopt an individualized approach in SSI for aggressive children by highlighting different characteristics of two types of aggression, which have been much discussed in child development literature. We further suggest that social skills training produces greater behavioral change 
when the training is sensitive to the needs of each individual child.

Although this review was limited to the social skills training context, empirical research findings indicate that social skills training appears to be most effective when provided with other intervention programs such as parenting training and teacher consultation. The review of PA and RA certainly suggests that in addition to social skills intervention, a number of contextual variables should be addressed as a part of that intervention. For example, parents' endorsement and model of antisocial or hostile behaviors will certainly overpower improvement, if any, acquired through SSI. Therefore, relying on SSI alone for reducing proactive aggression is most likely to result in disappointing outcomes.

Social skills intervention is a valuable choice available for school practitioners when replacing interpersonally hostile, aggressive behaviors of young children with more socially competent behaviors. The present discussion certainly points out that a thorough assessment should be conducted to identify specific aims for SSI and that intervention should be carefully designed accordingly.

\section{References}

Achenbach, T. M. (1983). Child Behavior Checklist for Ages 4-18 (CBCL/418). Burlington, VT: University Medical Education.

Arnold, M.E. \& Hughes, J.N. (1999). First do no harm: Adverse effects of grouping deviant youth for skills training. Journal of School Psychology, 37 (1), 99-115.

Bandura, A. (1973). Aggression: A social learning analysis. Englewood Cliffs, NJ: Prentice-Hall.

Beelmann, A., Pfingsten, U., \& Lösel, F. (1994). Effects of training social competence in children: A meta-analysis of recent evaluation studies. Journal of Clinical Child Psychology, 23, 260-271.

Bierman, K. L., \& Furman, W. (1984). The effects of social skills training and peer involvement on the social adjustment of preadolescents. Child Development, 55, 151-162.

Brown, K., Atkins, M. S., Osborne, M. L., \& Milnamow, M. (1996). A revised teacher rating scale for reactive and proactive aggression. Journal of Abnormal Child Psychology, 24, 473-480.

Chandler, M. J. (1973). Egocentrism and antisocial behavior: The assessment and training of social perspective-taking skills. Developmental Psychology, 9, 326-332.

Crick, N. R., \& Dodge, K. A. (1996). Social information-processing mechanisms in reactive and proactive aggression. Child Development, 67, 993-1002.

Day, D. M., Bream, L. A., \& Pal, A. (1992). Proactive and reactive aggression: An analysis of subtypes based on teacher perspectives. Journal of Clinical Child Psychology, 21, 210-217.
Dodge, K. A., \& Coie, J. D. (1987). Social informationprocessing factors in reactive and proactive aggression in children's peer group. Journal of Personality and Social Psychology, 53, 1146-1158.

Dodge, K. A., Coie, J. D., Pettit, G. S., \& Price, J. M. (1990). Peer status and aggression in boy's groups: Developmental and contextual analysis. Child Development, 61, 1289-1309.

Elliot, S. N., Sheridan, S. M., \& Gresham, F. M. (1989). Assessing and treating social skills deficits: A case study for the scientist-practitioner. Journal of School Psychology, 27, 197-222.

Greenburg, M. T., Kusche, C. A., Cook, E. T., \& Quamma, J. P. (1996). Promoting emotional competence in school-aged children: The effect of the PATHS curriculum. Development and Psychopathology, 7, 117-136.

Gresham, F. M. (1998). Social skills training: Should we raze, remodel, or rebuild? Behavioral Disorders, 24, $19-25$.

Hartup, W. W. (1974). Aggression in childhood: Developmental perspectives. American Psychologist, 29, 337-341.

Henington, C., Hughes, J.N., Cavell, T.A., \& Thompson, B. (1999). The role of relational aggression in identifying aggressive boys and girls. Journal of School Psychology, 36(4), 457-477.

Lochman, J. E. \& Lenhart, L. A. (1993). Anger coping intervention for aggressive children: Conceptual models and outcome effects. Clinical Psychology Review, 13(8), 785-805.

Loeber, R. (1990). Development and risk factors of juvenile antisocial behavior and delinquency. Clinical Psychology Review, 10(1), 1-41.

Poulin, F. \& Boivin, M. (2000). Reactive and proactive aggression: Evidence of two-factor model. Psychological Assessment, 12, 115-122.

Price, J. M., \& Dodge, K. A. (1989). Reactive and proactive aggression in childhood: Relations to peer status and social context dimensions. Journal of Abnormal Child Psychology, 17, 455-471.

Prinz, R. J., Blechman, E. A., \& Dumas, J. E. (1994). An evaluation of peer coping-skills training for childhood aggression. Journal of Clinical Child Psychology, 23, 193-203.

Reynolds, C. R. \& Kamphaus, R. W. (1992). Behavior assessment system for children. Circle Pines, MN: American Guidance Service, Inc.

Schwartz, D., Dodge, K. A., Coie, J. D., Hubbard, J. A., Cillessen, A. H. N., Lemerise, E. A., \& Bateman, H. (1998). Social cognitive and behavioral correlates of aggression and victimization in boys' play groups. Journal of Abnormal child Psychology, 26(6), 431-440.

Sheridan, S.M., Hungelmann, A., \& Maughan, D.P. (1999). A contextualized framework for social skills assessment, intervention, and generalization. School Psychology Review, 28(1), 84-103.

Sheridan, S. M., \& Walker, D. (1999). Social skills in context: Considerations for assessment, intervention, and generalization. In C. R. Reynolds \& T. B. Gutkin (Eds.), The handbook of school psychology (3rd ed., pp. 686-708). New York: Wiley \& Sons.

Smithmyer, C. M., Hubbard, J. A., \& Simons, R.F. (2000). Proactive and reactive aggression in delinquent adolescents: Relations to aggression outcome expectancies. Journal of Clinical Child Psychology, 29(1), 86-93.

Waschbusch, D.A., Willoughby, M.T., \& Pelham, W.E., Jr. (1998). Criterion validity and the utility of reactive and proactive aggression: Comparisons to attention deficit hyperactivity disorder, oppositional defiant disorder, conduct disorder, and other measures of functioning. Journal of Clinical Child Psychology, 27(4), 396-405. 